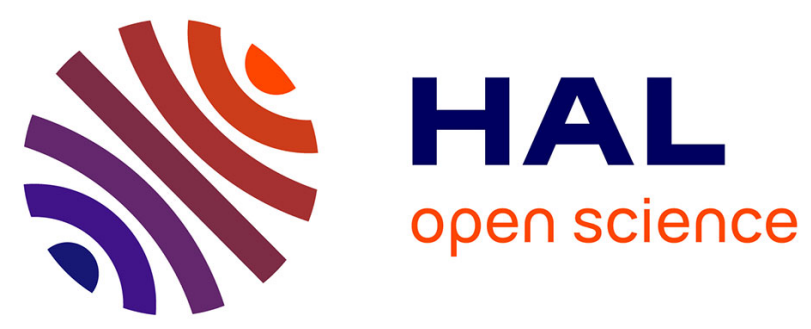

\title{
Chapitre IV : Perspectives
}

François Le Tacon

\section{To cite this version:}

François Le Tacon. Chapitre IV: Perspectives. 1995, pp.147-148. 10.4267/2042/26706 . hal03444316

\section{HAL Id: hal-03444316 \\ https://hal.science/hal-03444316}

Submitted on 23 Nov 2021

HAL is a multi-disciplinary open access archive for the deposit and dissemination of scientific research documents, whether they are published or not. The documents may come from teaching and research institutions in France or abroad, or from public or private research centers.
L'archive ouverte pluridisciplinaire HAL, est destinée au dépôt et à la diffusion de documents scientifiques de niveau recherche, publiés ou non, émanant des établissements d'enseignement et de recherche français ou étrangers, des laboratoires publics ou privés. 


\section{Chapitre IV \\ PERSPECTIVES}

Les modèles actuels de croissance des peuplements ou de prévision de la qualité des bois sont supérieurs aux outils qui étaient jusqu'à maintenant mis à la disposition des gestionnaires forestiers comme les tables de production qui sont des modèles simples essentiellement quantitatifs. Ces nouveaux modèles sont cependant encore très imparfaits car ils restent des boîtes noires; pour les améliorer, différentes approches sont possibles ; celle qui paraît la plus prometteuse est l'incorporation de données fonctionnelles de nature essentiellement physiologique. Trois articles proposent une telle intégration : celui de Christine Deleuze qui propose d'intégrer le bilan carboné, celui de Noël Le Goff, André Granier, Jean-Marc Ottorini, Karinne Le Gall et Marianne Peiffer qui proposent d'intégrer la photosynthèse et le bilan hydrique et celui de Francis Colin, de Frédéric Danjon et de Léon Wehrlen qui proposent de prendre en compte le fonctionnement du système racinaire.

La plupart des modèles actuels ne prennent en compte que les peuplements équiennes. Benoît Courbaud propose un modèle pour les pessières irrégulières de montagne. Alain Franc, Jérôme Besnard et Emmanuel Klein proposent d'améliorer l'outil mathématique et analysent des modèles s'inspirant de démarches qui ont été utilisées dans l'étude des systèmes complexes. Ces modèles sont aussi applicables aux peuplements forestiers hétérogènes.

Enfin Frédéric Danjon propose de prendre en compte les gains obtenus par amélioration génétique et de les intégrer dans les modèles de croissance. 
